\title{
An Investigation into the Effect of Audit Quality on Accounting Conservatism in Companies Listed in Tehran Stock Exchange
}

\author{
Mahdi Mohammadinejad Pashaki, Sina Kheradyar \\ Department of Accounting, Rasht Branch, Islamic Azad University, Rasht, Iran \\ E-mail address: mohamadinejad_mehdi@yahoo.com
}

\begin{abstract}
Keywords: Accounting Conservatism, Industry- Specialist Auditor, Auditor Rank, Auditor Tenure.
\end{abstract}
\begin{abstract}
The present study sought to investigate the effect of audit quality on accounting conservatism in Iranian capital market. In this study, given the hypotheses and theoretical foundations of the study, three hypotheses were formulated and the effect of each of the factors of industry-specialist auditor, auditor rank, and auditor tenure was examined on accounting conservatism of companies. The period for investigation was from 2009 to 2013. Its population was determined as all companies listed in Tehran Stock Exchange and the statistical sample of the study included 100 companies. The data required for this study were extracted from website of Tehran Stock Exchange and after collecting events through available resources and entering data in Excel software; its functions were used to calculate the variables of the study. Then, the results from measuring variables were entered into Eviews software for statistical calculations and the relationship between variables were evaluated using this software. The results of the study showed that there is a positive relationship between accounting conservatism and auditing attributes such as auditor rank and auditor tenure. Also, the obtained results indicated that there is no significant relationship between accounting conservatism and customer industry-specialist auditor.
\end{abstract}

\section{INTRODUCTION}

An independent and skillful audit institution is able to recognize misrepresentation of addressed financial statements and can be effective on its correct presentation to its employer so that the reliable financial information is reported. To achieve this desired objective completely depends upon attributes of audit institutions which can positively or negatively be associated with audit quality. According to Titman \& Truman (1989), audit with more quality improves the accuracy of the provided information and let investors obtain more accurate estimation from the company's value (Pour karim, 2009, PP.3).

Need for conservatism is suggested with agency theory through which problems between managers and stakeholders on the separation of management and ownerships be solved. This issue was discussed by Watts (2003) with the assumption that the financial reports published by managers were conservative and shareholders may reduce salary of managers to compensate difference from their attention to their personal interests. To prevent this situation, managers may provide more conservative volume as a sign of their lack of attention to their own personal interests.

Audit quality and accounting conservatism has been discussed and studied in financial meetings for a long time and it seems that both can influence the capital market. Accordingly, many studies have been done on audit quality, auditor's ability to detect fraud, and ultimately, insuring appropriate audit opinion on financial statements. Many accounting scandals and bankruptcies in financial markets have occurred in recent years; however, the most important results which have not been expected for these events was to increase warning the importance of auditors' role and their vital role in the performance of many sections of financial markets (Hamdan, 2010). These events led to the proliferation demand for increasing audit quality and effect. However, there is no consensus on the concept of audit quality and International Federation of Accountants (IFAC) and 
American Institute of Certified Public Accountants (AICPA) could not introduce a clear concept of audit quality.

Issa (2008) defines audit quality: it means the ability of audit process to detect and report important falsification of financial statements as well as to reduce asymmetry of information between managers and stakeholders that are relevant to the level of quality of information in financial statements.

Previous studies have separately examined the relationship between conservatism and one of the attributes of audit quality such as the size of company or auditor tenure. This study aimed to investigate the effect of several attributes of audit quality on accounting conservatism. Definition of the quality of accounting information is not so simple. A disclosed event or trade measured in accordance with specific accounting standards may be evaluated well by a representative and bad for another. Accounting conservatism can be inherent feature of any economic area. Many studies have been conducted on the effect of the size of auditing company on the quality of financial information. According to D'Angelo, audit quality has been made up of the common possibility that auditor can detect and report significant errors in accounting system. The discovery of significant errors is related to the technical competition while exposing to these errors refers to the independence of auditor (Hamdan, 2010).

Generally, the concept of accounting conservatism is that the company should report at least the value of the assets and revenues, in other words, at most the value of debts and costs. Accounting conservatism is one of the basic assumptions of financial report indicating the willingness of company to quickly identify bad news than good ones (Basu, 1997).

Audit quality is a prerequisite for many sectors. Audit quality is weighting factor of audit companies for competing between them. Conservatism traditionally predicts no profit but all losses Rules of standards and principles of accounting differ in various countries. Many of countries apply the private sector while the rest use the public sector. They all try to provide the best possible quality of accounting information assisting to make decisions despite their various objectives. In Conceptual Financial Statement 2, Financial Accounting Standards Board (FASB) stated that possible standards should be led to reduce net income and assets but not increase them in a comparative study that conducted on accounting rules of private and public sectors by Ball et al (2008). They found that accounting policies for private sector is more conservative than accounting ways of public sectors.

Hendrickson (1982) found that one aspect of conservatism is pessimism rather than optimism during preparing financial reports. Measure of accounting conservatism helps to measure the performance of emerging markets in companies listed in Tehran Stock Exchange. A bulk of research shows that the price of efficient market stock reflects all available information at the appropriate time (Yasin, 2008).

We examine the discussed problem by answering the following question:

Does audit quality affect the conservatism of the companies listed in Tehran Stock Exchange?

In this study, approaches leading to distinguish the audit quality of companies from each other will be identified and factors explaining these differences will empirically be examined. In this study, industry- specialist auditor, auditor rank, and auditor tenure will be considered and reviewed and the impact of each on accounting conservatism will be addressed.

\section{PREVIOUS RESEARCH}

Evaluating the effect of audit quality on accounting conservatism has been the subject of studies by many researchers so that many theories and views have so far been made in this relation.

Watts et al (2001), Watts (2003), and Bal and Komar Shiva (2005) suggested that conservatism is important in the creation of contractual relationships between companies and their creditors in order to ensure the minimum guarantees for the fulfillment of obligations and reduction of possibility of improper distribution of cash in some representatives. Conservatism increases the 
efficiency of accounting information by reducing the optimistic management of company's results. Discussion on the advantages of accounting information is still as an inconclusive matter. Conservatism impacts the audit quality because it is limited to manipulate accounting information.

The results of the studies show the importance of accounting conservatism on the fate of the company. On the other hand, there are still many unknown aspects on audit quality and factors affecting it which makes study in this field completely essential.

According to Sonder (1997), the main feature of the audit of company is to assess the accounting system. Audit decreases the information asymmetry through an access to the reported financial information. Sonder warns that decisions of most auditors are based on their beliefs and judgments about the reported financial statements and financial and economic aspects of clients. In addition, the judgment is related to the auditor's experience and relationship with audited company. Becker et al (1998) indicated that the audited companies have less optimistic behavior by greater audit companies

Watts et al (2001), Watts (2003), and Bal and Komar Shiva (2005) suggested that conservatism is important in the creation of contractual relationships between companies and their creditors in order to ensure the minimum guarantees for the fulfillment of obligations and reduction of the possibility of improper distribution of cash in some representatives.

Conservatism increases the efficiency of accounting information by reducing the optimistic management of company's results. Francis and Wang (2008) observed that in companies audited by a large audit company with high credit rate, the identification of loss is done more timely. In his study, Hamdan (2010) concluded that conservatism can help to improve the quality of financial reports. He also recognized a correlation between high level of accounting conservatism in industrial companies in Bahrain and the improvement of view of foreign auditors. Hogan and jitter (1999) and Bannister and West (2001) revealed that audit quality reduces smoothing of profit and in some cases, makes it limited. Basu et al. (2002), Chang et al (2003), and Jenkins et al (2007) found that companies audited by large auditors highly tend to impose conservatism. On the relationship between auditor tenure and conservatism, Hamilton et al (2005) and Lee (2007) concluded that conservatism is reduced by increasing auditor tenure. Jenkins and Vallauris (2006) believed that long-term interactions of auditor and employer lead to increase in the use of conservative procedures by employer. They argue that since new auditors lack sufficient knowledge about business activities and internal control systems of employers, they force to rely more on managers' decisions in relation to financial reporting and thus, there is more possibility that they agree with opportunistic procedures of managers. This can lead to reduce the use of conservative procedures; however, by increasing auditor tenure and achieving greater recognition, their consciousness on work become more and they avoid any potential audit risk and request manager the use of more conservative procedures. In their study, Abraham and Saiidi (2008) evaluated the effect of the type of audit institute and type of view of audit report on discretionary accruals. They concluded that only the type of audit institution is associated with discretionary accruals. Rezazade and Azadi (2008) conducted a study entitled the relationship between asymmetry of conservatism information in financial reporting. The results indicated that there is a significant and positive correlation between the information asymmetry of investors and the level of conservatism applied in financial statements. Mehrani et al (2009) examined the relationship between conservatism and the interest accruals. The results of the study showed that the accounting profit of companies is more sensitive to negative returns (compared to positive returns) and accruals explain major part of asymmetric timeliness in interest. Karami and Bazrafshan (2009) found a direct and significant relationship between auditor tenure and conservatism. The findings of the study explain that conservatism has been less in short auditor tenure and auditor mandatory rotation has opposite effect on conservatism. 


\section{HYPOTHESES}

1- There is a significant relationship between industry- specialist auditor and accounting conservatism.

2- There is a significant relationship between auditor rank and accounting conservatism.

3- There is a significant relationship between auditor tenure and accounting conservatism.

\section{RESEARCH METHOD}

In this study, the studied population is companies listed in Tehran Stock Exchange from 2009 to 2013. With regard to the duration of the study period, samples should be selected so that at this time, they have been active market to provide the possibility of testing hypotheses. Sampling method will be systematic elimination method. In so doing, the following limitations have been applied to select the samples:

1- Companies listed in Stock Exchange before 2009 and their stock was traded at the beginning of 2009.

2- For uniformity, it necessary to access the financial statements and explanatory notes attached to them.

3- Fiscal year of all companies should be ending in March of each year and that the fiscal year should not have been changed during 2009 to 2013.

4- Investment, intermediation, holding, and leasing companies, banks, and financial and insurance institutions were excluded from the sample.

5- Companies should not have stop trading more than 6 months.

After considering all the above criteria, 100 companies remain as population that all of them have been selected as the study sample. Therefore, our observations reached 500 yearcompany.

\subsection{Investigating the normality of the distribution of dependent variable}

Normality of residuals to the regression model is one of the regression hypotheses which indicate the validity of regression tests. In the following, using Kolmogorov-Smirnov test, the normality of the distribution of dependent variables is evaluated because the normality of dependent variables leads to the normality of residuals of the model (the difference of estimated values with real values). Null- and Alternative- hypothesis in this test is written as follows:

$\mathbf{H}_{\mathbf{0}}$ : Data follow normal distribution for dependent variable

$\mathbf{H}_{1}$ : Data do not follow normal distribution for dependent variable

Table 1. Kolmogorov-Smirnov test to study the normality of dependent variable of the study

\begin{tabular}{|l|l|l|l|l|l|l|l|l|}
\hline \multirow{2}{*}{ Variable } & \multirow{2}{*}{ Number } & \multicolumn{3}{|l|}{ Normal parameters } & \multicolumn{2}{l|}{ Highest difference } & \multirow{2}{*}{ Z value of } & Probability \\
\cline { 3 - 9 } & & Mean & SD & $\begin{array}{l}\text { Absolute } \\
\text { value }\end{array}$ & Positive & Negative & Kolmogorov- \\
Smirnov & value \\
\hline AC & 500 & 582495 & 2425865 & 0.36 & 0.35 & $-0 / 36$ & 8.11 & 0.000 \\
\hline Ln (AC) & 500 & 12.40 & 1.42 & 0.06 & 0.06 & -0.04 & 1.34 & 0.056 \\
\hline
\end{tabular}

The probability value is 0.000 for dependent variable which is less than 0.05 . So, the null hypothesis (normality of variable) is rejected for this variable; however, the value of the probability of the algorithm is 0.056 for this variable which is higher than 0.05 i.e. the distribution of the logarithm of this variable is normal according to the prediction (skew and elongation close to zero). In the following histogram, it has been shown that the distribution of the dependent variable has skew distribution to the right. 


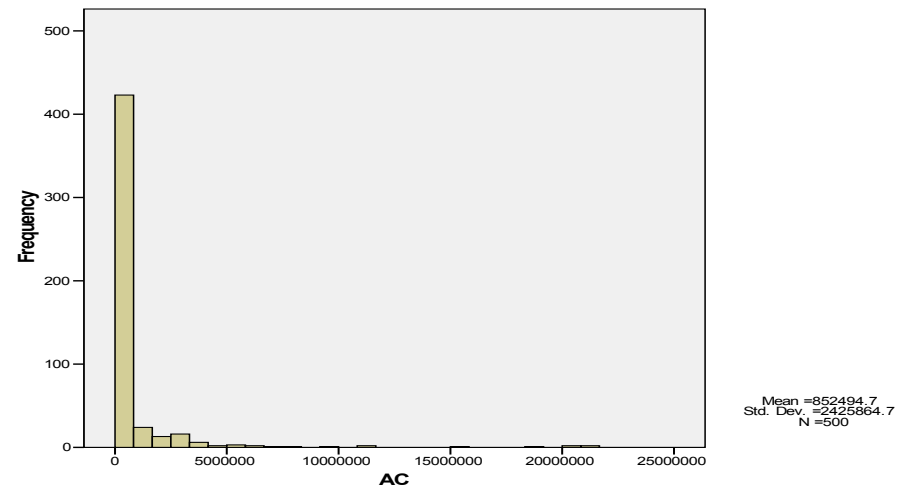

Diagram 1. Histogram of the distribution of dependent variable

In the following histogram, it seems the distribution of the dependent variable is approximately normal i.e. the logarithm of the variable is normal.
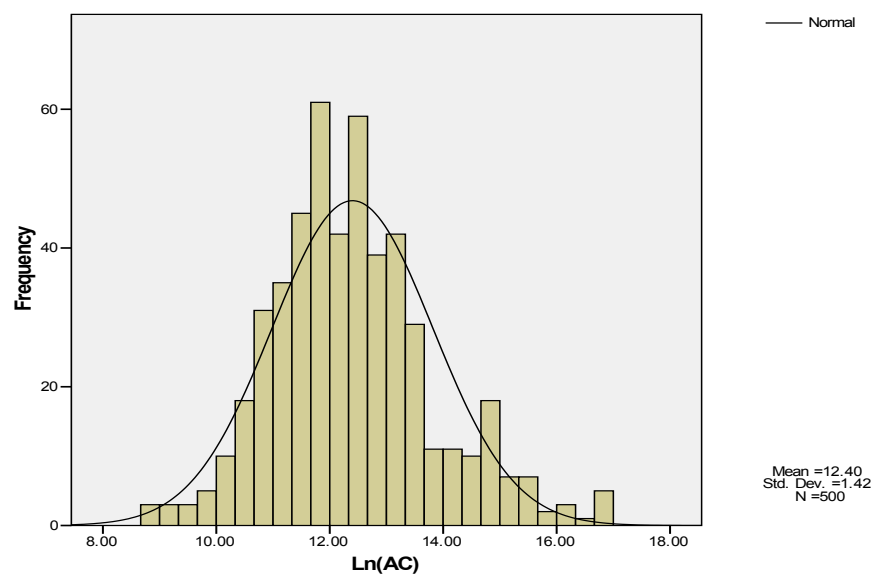

Diagram 2. Histogram of the approximate normality of the distribution of dependent variable

\subsection{Panel analysis}

In the panel analysis, data were collected as cross section-time series that is the collected data are for different crosses (here, companies) over the time. In data collected in this way, the independence of observations will not be preserved because several interdependent (because of belonging to a company) observations of each company have been repeated for several years.

In the discussions of panel analysis, there are three types of model without fixed effects, with fixed effects and with random effects and different tests are used to recognize the appropriate model. These tests are briefly discussed below:

\subsection{The process of selecting an appropriate model}

The process of selecting the appropriate model is as follows:

The first stage: the presence of effects is tested against model without effects (Chow or Hausman test). In this stage, testing the hypothesis is as follows:

$$
\begin{cases}H_{0}: & \text { Integrated model is appropriate. } \\ H_{1}: & \text { Model with effects is appropriate. }\end{cases}
$$

If probability value is less than 0.05 for the above test, the null hypothesis is rejected at the level of significance of $95 \%$ that is the model with fixed or random effects is appropriate; otherwise, the 
null hypothesis is not rejected at the level of significance of $95 \%$ that is the integrated model is appropriate.

The second stage: random effects are tested against the model with fixed effects (Hausman test).

If the used model is the model with effects, the next question will be whether the model with fixed effects or the model with random effects is appropriate.

In this test, the Null- hypothesis and Alternative- hypothesis are as follows.

$\left\{\begin{array}{l}H_{0}: \text { Model with the random effects are appropriate } \\ H_{1}: \text { Model with the fixed effects are appropriate }\end{array}\right.$

If probability value is less than 0.05 for the above test, the null hypothesis is rejected at the level of significance of $95 \%$ i.e. the model with fixed effects is appropriate; otherwise, the null hypothesis is not rejected at the level of significance of $95 \%$ that is the model with random effects is appropriate.

Finally, out of three models without effects, model with fixed effects, and model with random effects, the most appropriate model is chosen and the significance of each of independent and control variables will be discussed.

\subsection{Selecting the model}

As it has previously been said, an appropriate model is selected among from these models (integrated model, fixed model or random effects model) Results of Chow and Hausman test for identifying the appropriate model have been presented in the table below:

Table 2. Chow and Hausman test to select the appropriate model

\begin{tabular}{|c|c|c|c|c|c|c|c|}
\hline \multicolumn{4}{|c|}{ Chow of Limer test } & \multicolumn{3}{|c|}{ Hausman test } & \multirow[t]{2}{*}{ result } \\
\hline Effects test & value & $\begin{array}{l}\text { Degree of } \\
\text { freedom }\end{array}$ & $\begin{array}{l}\text { Probability } \\
\text { value }\end{array}$ & $\begin{array}{l}\text { Chi-squared } \\
\text { value }\end{array}$ & $\begin{array}{l}\text { Degree of } \\
\text { freedom }\end{array}$ & Probability value & \\
\hline F-value & 68.351 & $(99,397)$ & 0.000 & \multirow[t]{2}{*}{21.12} & \multirow[t]{2}{*}{3} & \multirow[t]{2}{*}{0.000} & \multirow{2}{*}{$\begin{array}{l}\text { Model with } \\
\text { fixed effects }\end{array}$} \\
\hline $\begin{array}{l}\text { Chi-squared } \\
\text { value }\end{array}$ & 1446.428 & 99 & 0.000 & & & & \\
\hline
\end{tabular}

The probability value of Chow test is less than 0.05 . Therefore, the applied model has separated effects for the companies.

The probability value of Hausman test is less than 0.05 (its value is equal to 0.000 ). Therefore, the used model is a model with fixed effects. In the following, this model is used to examine the hypotheses.

\subsection{Fitting the model with fixed effects}

In this section, Panel Analysis has been used to investigate and estimate the general model. The assumed model is as follows:

$$
\operatorname{Ln}\left(A C_{i t}\right)=\beta_{0}+\beta_{1} S P_{i t}+\beta_{2} A Q_{i t}+\beta_{3} A R_{i t}+\varepsilon_{i t}
$$

Null- and Alternative-hypotheses in this model are as following:

$\left\{\begin{array}{l}H_{0}: \beta_{1}=\beta_{2}=\beta_{3}=0 \\ H_{1}: \beta_{i} \neq 0 \quad i=1,2,3,\end{array}\right.$

$\begin{cases}H_{0}: & \text { There is no significant model. } \\ H_{1}: & \text { There is a significant model. }\end{cases}$ 
In the following table, results of Panel Analysis have been given:

Table 3. Fitting the model for the model

\begin{tabular}{|l|c|c|c|l|}
\hline Parameters & Coefficient's value & t-value & Probability value & Result \\
\hline Fixed value & 0.39 & 0.47 & 0.638 & Non-significant \\
\hline SP & -0.472 & -1.464 & 0.144 & Non-significant \\
\hline AQ & 0.186 & 2.780 & 0.006 & Significant and positive \\
\hline AR & 0.073 & 4.480 & 0.000 & Significant and positive \\
\hline F-value & 78.68 & Probability of F- value & 0.000 \\
\hline $\begin{array}{l}\text { Coefficient of } \\
\text { determination }\end{array}$ & 0.95 & Durbin-Watson & 1.65 \\
\hline
\end{tabular}

In the above table, the model has been estimated with fixed effects and the probability of significance of $\mathrm{F}$ is equal to 0.000 that is less than 0.05 . Therefore, the null hypothesis is rejected at the confidence level of $95 \%$ i.e. there is a significant model at the confidence level of $95 \%$. The coefficient of determination is equal to 0.95 that is about $95 \%$ of changes in the independent variable is explained by independent and control variables. Value of Durbin-Watson statistics is equal to 1.64 that is values close to 2 indicate autocorrelation of residuals which is one of the assumptions of regression (So, there is no autocorrelation between residuals).

To estimate the coefficients, the following assumptions can be considered using t-statistics, null hypothesis for y-intercept or fixed value as follows:

$$
\left\{\begin{array}{l}
H_{0}: \beta_{0}=0 \\
H_{1}: \beta_{0} \neq 0
\end{array}\right.
$$

And for the rate of the relationship between independent and control variables, it is written as follows:

$$
\begin{array}{r}
\left\{\begin{array}{l}
H_{0}: \beta_{1}=0 \\
H_{1}: \beta_{1} \neq 0
\end{array}\right. \\
\left\{\begin{array}{l}
H_{0}: \beta_{3}=0 \\
H_{1}: \beta_{3} \neq 0
\end{array}\right.
\end{array}
$$

The value of the test statistics is calculated as follows:

$$
t_{\beta_{i}}=\frac{\beta_{i}-0}{S_{\beta_{i}}} i=0,1,2,3
$$

The distribution of the above statistics is standard normal distribution for large samples. Therefore, the reject and non-reject areas will be as following.

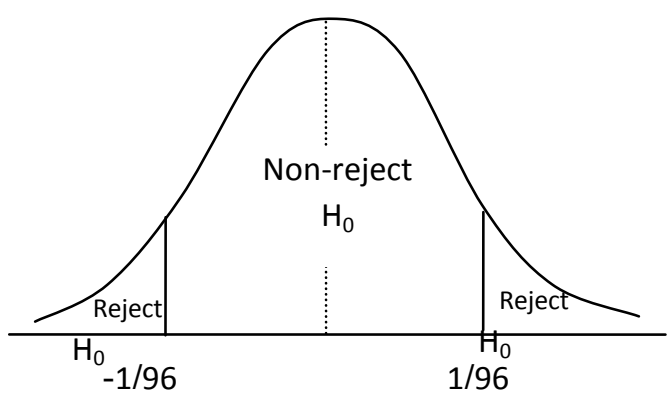

Diagram 4-3. Standard normal distribution 
The judgment is in a way that if t-value is in reject-area; the null hypothesis is rejected. In the above table, the relationship between the independent and dependent variables has been specified. A significant and positive relationship means that by increasing the independent variable, the dependent variable increases, while in the significant and negative relationship, the dependent variable decreases by increasing the independent variable and in a non-significant relationship, there is no relationship between the independent and dependent variables.

The t-statistic is equal to -1.46 (non-significant) for SP, 2.78 (significant and positive) for AQ, 4.48 (significant and positive) for AR, and 91.19 for y-intercept which is the area of null hypothesis at the level of significant of $95 \%$ that is y-intercept is significant.

\subsection{The validity of the model}

The validity of the estimated models depends on the rate of establishing presuppositions required for estimating the model that the most important of these assumptions include:

1. The normality of residuals

2. The homogeneity of variance

3. The lack of autocorrelation of residuals

4. The presence of linear relationship and no outliers

5. The absence of collinearity among independent variables

In this study, through diagnostic tests and diagrams, the establishment of presuppositions has been investigated.

1. Kolmogorov-Smirnov test

2. Reminding diagram versus estimated values (the lack of pattern in this diagram shows homogeneity of variance. These diagrams have been presented in Appendix)

3. Durbin-Watson test (values close to 2 indicates the absence of autocorrelation)

4. Scatter diagrams

Correlation matrix has been used.

\section{CONCLUSIONS AND SUGGESTIONS}

According to the results of the tests, to determine the estimation method described in Chapter IV as well as the selected appropriate methods, the results of testing the hypotheses in the present study include:

In the first hypothesis, the relationship between industry-specialist auditor and accounting conservatism for companies in this study was tested that this relationship was not statistically significant.

Recent studies suggest that there is a positive relationship between the type of auditor specialty and quality of the audit report. In other words, because of having a greater ability to identify and deal with special problems of the industry, auditors specialized in the desired industry can do audit with better quality. In addition, the more the auditing institute achieves experience in a particular industry; the more it will become interested in offering auditing services with superior quality because of more reputation (Mojtahedzade and Aghai, 2004).

In the second hypothesis, with respect to statistical results, the relationship between auditor rank and accounting conservatism was estimated as positive and significant that is consistent with the studies by Becker et al (1998), Basu et al (2002), Chang et al (2003), Jenkins et al (2007), Francis and wang (2008), and Salehi et al (2010). The second hypothesis states that in companies audited by a large audit company, recognition of loss is timelier done at lower levels than positive behavior.

In the third hypothesis, according to the statistical results, the relationship between auditor tenure and accounting conservatism was assessed as positive and significant. The results were not consistent with the studies by Hamilton et al (2005) and Lee (2007) because they concluded that 
based on the relationship between auditor tenure and conservatism, conservatism is decreased by increasing auditor tenure. Also, the results of the study were consistent with those by Jenkins and Vallauris (2006) and Karami and Bazrafshan (2009).

Because they believe that long-term interactions of auditor and employer lead to increase the use of conservative procedures by employer and it is observed that by increasing auditor tenure, conservatism is increased as well. The findings of the present study prove that in short term auditor tenure, conservatism has been lower and by increasing auditor tenure, using conservative procedures is increased by the employer.

\section{SUGGESTIONS}

\subsection{Suggestions with regard to the study findings}

1- Given the positive relationship between accounting conservatism and audit quality, the users of the applied results of the study are suggested to pay attention to the related behavioral reaction in their assessments and decisions. If accounting conservatism declines in market due to internal and external factors of company, audit with high quality can improve this decline.

2- Due to the fact that auditor who is specialized in a particular industry causes more reliability compared to other institutions, it is recommended that companies which have more specialty than other competitors be invited for auditing

3- Since audit institutions with higher rank (such as audit organization) increase the reliability of financial statements compared to other institutions and according to the results from testing the second hypothesis of this study, it can be said that company's financial statements audited by auditors with better quality (large audit institutions such as organization) will have more accurate predictions and more detailed financial information. Therefore, General assemblies of companies can be recommended to use larger auditing institutions. Stock Exchange organization can also be suggested to pay more attention to institutions with higher rank in choosing trusted institutions of stock exchange

\subsection{Suggestions for further research}

1- It is suggested that the role of corporate governance mechanism with audit quality be tested in investigating accounting conservatism.

2- It is suggested that according to the size of the company, the role of audit quality in applying accounting conservatism be investigated to determine the relationship between accounting conservatism and audit quality in large and small companies.

3- It is suggested that according to the type of industry, the role of audit quality in applying accounting conservatism be investigated in order to determine the interaction between conservatism and audit quality in various industries.

4- It is suggested that the role of audit quality in applying accounting conservatism be investigated using financial information of companies active in Over the Counter (OTC). 


\section{References}

[1] Ball, R. and Shivakumar, L. (2006) 'The role of accruals in asymmetrically timely gain and loss recognition', Journal of Accounting Research, 44(2), pp. 207-42.

[2] Ball, R., \& Brown, P. (1968). An empirical evaluation of accounting income numbers. Journal of Accounting Research, 6(2), 159-178.

[3] Ball, R., \& Shivakumar, L. (2005). Earnings quality in UK private firms: Comparative loss recognition timeliness. Journal of Accounting and Economics, 39(1): 83-128.

[4] Basu, S. (1997). The conservatism principle and the asymmetric timeliness of earnings. Journal of Accounting and Economics, 24(1), p.3-37.

[5] Chung, R., Firth, M. and Kim, J. -B. (2003) 'Auditor conservatism and reported Earnings', Accounting and Business Research, 33(1), pp. 19-32.

[6] Dechow, P., Kothari, S. P., \& Watts, R. L. (1998). The relation between earnings and cash flows. Journal of Accounting and Economics, 25, 133-168.

[7] Ebrahimi Kordlar A. and Seyedy S.A., (2008), “Independent Auditor's Roles in Decreasing Discretionary Accrual", Journal of The Accounting and Auditing Review, No. 54, Pp. 4-16.

[8] Francis, J. and Wang, D. (2008) 'The joint effect of investor protection and Big 4 audits on earnings quality around the world', Contemporary Accounting Research, 25(1), pp. 157-91.

[9] Hamadan, A. (2010). The Impact of Accounting Conservatism on the Enhancement of the Quality of Financial Reporting: an empirical study from the Jordanian industrial corporations. Dirasat of Administrative sciences.

[10] Issa, Samir M. (2008), The Impact of external audit on the operation of earnings managementApplied study. Journal

[11] Jenkins, D. S., \& Velury, U. (2008). Does auditor tenure impact the reporting of conservative earnings? Journal of Accounting and Public Policy, 27(2), 115-132.

[12] Karami, Gh., and Bazrafshan, A., (2009), "On the Relationship between Auditor Tenure and the Reporting of Conservative Earnings in Tehran Stock Exchange", Quarterly Journal of Escurities Exchange, No. 2(7), Pp. 55-80

[13] Mehrani, S., Moradi, M., and Eskandar, H., (2010), "The Relationship between Type of Institutional Ownership and Conservative Accounting”, Financial Accounting Researches, Second year, No. 1 (3), Pp. 47-62

[14] PourKarim E., (2009), "Investigation of the Effect of Audit Quality on Accrual Reliability in Companies Listed in Tehran Stock Exchange", M.A Thesis, Islamic Azad University, Tabriz Branch

[15] Rezazadeh J., and Azad A., (2008), "The Link between Information Asymmetry and Conservatism in Financial Reporting", Journal of The Accounting and Auditing Review, No. 15 (54), Pp. 63-80 
[16] Salehi M., Jabbarzade Kangarloi S., and Alizade N., (2010), "Investigating the Relationship between Audit Quality and Conditional and Unconditional Conservatism in Financial Reporting”, Journal of Accounting and Auditing, Imam Reza International University.

[17] Wang, K., \& Wong, T. J. (2003). From government to corporation: largest shareholder's change and firm performance. Unpublished working paper, Tsinghua University and Hong Kong University of Science and Technology.

[18] Watts, R. L. (2003). Conservatism in accounting part I: explanations and implications. Accounting Horizons, 17(3), 207-221. 